\title{
The Summit Score Stratifies Mortality and Morbidity in Chronic Obstructive Pulmonary Disease
}

This article was published in the following Dove Press journal:

International Journal of Chronic Obstructive Pulmonary Disease

\author{
Benjamin D Horne $\mathbb{D}^{1,2}$ \\ Matthew J Hegewald (D) ${ }^{3}$ \\ Courtney Crim $\mathbb{D}^{4}$ \\ Susan Rea ${ }^{5}$ \\ Tami L Bair ${ }^{\prime}$ \\ Denitza P Blagev (iD ${ }^{3}$
}

'Intermountain Medical Center Heart Institute, Salt Lake City, UT, USA;

${ }^{2}$ Division of Cardiovascular Medicine,

Department of Medicine, Stanford

University, Stanford, CA, USA; ${ }^{3}$ Division

of Pulmonary Medicine, Department of

Internal Medicine, Intermountain Medical

Center, Salt Lake City, UT, USA;

${ }^{4}$ Research and Development,

GlaxoSmithKline, Research Triangle Park, NC, USA; ${ }^{5}$ Care Transformation, Intermountain Healthcare, Salt Lake City, UT, USA
Correspondence: Benjamin D Horne Intermountain Medical Center Heart Institute, $5|2|$ S. Cottonwood Street, Salt Lake City, UT 84107, USA

Tel +|80|-507-470|

Email benjamin.horne@imail.org

Twitter@DrBenjaminHorne
Introduction: Tobacco use and other cardiovascular risk factors often accompany chronic obstructive pulmonary disease (COPD). This study derived and validated the Summit Score to predict mortality in people with COPD and cardiovascular risks.

Methods: SUMMIT trial subjects $(\mathrm{N}=16,485)$ ages $40-80$ years with COPD were randomly assigned $50 \% / 50 \%$ to derivation $(\mathrm{N}=8181)$ and internal validation $(\mathrm{N}=8304)$. Three external COPD validations from Intermountain Healthcare included outpatients with cardiovascular risks $(\mathrm{N}=9251)$, outpatients without cardiovascular risks $(\mathrm{N}=8551)$, and inpatients $(\mathrm{N}=26,170)$. Cox regression evaluated 40 predictors of all-cause mortality. SUMMIT treatments including combined fluticasone furoate (FF) $100 \mu \mathrm{g} /$ vilanterol $25 \mu \mathrm{g}$ (VI) were not included in the score.

Results: Mortality predictors were $\mathrm{FEV}_{1}$, heart rate, systolic blood pressure, body mass index, age, smoking pack-years, prior COPD hospitalizations, myocardial infarction, heart failure, diabetes, anti-thrombotics, anti-arrhythmics, and xanthines. Combined in the Summit Score (derivation: $c=0.668$ ), quartile 4 vs 1 had $H R=4.43$ in SUMMIT validation $(p<0.001$, $95 \% \mathrm{CI}=3.27,6.01, \mathrm{c}=0.662)$ and $\mathrm{HR}=8.15$ in Intermountain cardiovascular risk COPD outpatients $(\mathrm{p}<0.001,95 \% \mathrm{CI}=5.86,11.34, \mathrm{c}=0.736)$, and strongly predicted mortality in the other Intermountain COPD populations. Among all SUMMIT subjects with scores 14-19, FF $100 \mu \mathrm{g} / \mathrm{VI} 25 \mu \mathrm{g}$ vs placebo had $\mathrm{HR}=0.76(\mathrm{p}=0.0158,95 \% \mathrm{CI}=0.61,0.95)$, but FF $100 \mu \mathrm{g} / \mathrm{VI} 25 \mu \mathrm{g}$ was not different from placebo for scores $<14$ or $>19$.

Conclusion: In this post hoc analysis of SUMMIT trial data, the Summit Score was derived and validated in multiple Intermountain COPD populations. The score was used to identify a subpopulation in which mortality risk was lower for FF $100 \mu \mathrm{g} / \mathrm{VI} 25 \mu \mathrm{g}$ treatment.

Trial Registration: The SUMMIT trial is registered at ClinicalTrials.gov as number NCT01313676.

Keywords: clinical decision tool, risk score, randomized controlled trial, Intermountain risk score, IMRS

\section{Plain Language Summary}

The Summit Score was derived and internally validated to predict mortality in the SUMMIT trial population and externally validated at Intermountain Healthcare. The Summit Score also predicted COPD exacerbations, cardiovascular events, and changes in spirometry findings.

\section{Introduction}

Chronic obstructive pulmonary disease (COPD) is a chronic, progressive lung disease often caused by tobacco use, a shared risk factor with cardiovascular disease that leads to a high rate of cardiovascular events and mortality. ${ }^{1,2}$ Cardiovascular disease 
is the second most common cause of death in COPD patients, ${ }^{3}$ and the most common cause of death in patients with moderate COPD. ${ }^{4,5}$ In non-COPD populations, measures of COPD severity such as spirometry parameters are independently predictive of cardiovascular outcomes. ${ }^{6,7}$ In COPD patients, mortality and other respiratory outcomes are also predicted by cardiovascular risk factors, including C-reactive protein, troponin, hypertension, and smoking. ${ }^{1,2,8}$ Due to its complexity, COPD may require use of risk predictors related to pulmonary and cardiovascular diseases and to systemic health that existing risk stratification tools do not employ.

A pragmatic parsimonious prediction tool, the Intermountain Mortality Risk Score (IMRS) was created using a broad spectrum of physiologic variables [ie, complete blood count $(\mathrm{CBC})$ and basic metabolic profile (BMP) parameters] to predict all-cause mortality in hospitalized patients. ${ }^{9}$ It has been validated in various populations, ${ }^{9-13}$ including pulmonary patients ${ }^{10}$ and external populations. ${ }^{9,14,15}$ Because CBC and BMP parameters can improve and deteriorate over time, IMRS can add unique risk information each time it is calculated. ${ }^{11}$ It also predicts common events and diagnoses, ${ }^{16}$ is used clinically, ${ }^{17}$ and modified versions such as the pulmonary IMRS (pIMRS) for lower-risk COPD exist. ${ }^{10,17-19}$

Unfortunately, the unique needs of patients with moderate severity COPD and cardiovascular risk factors may not be addressed by IMRS, pIMRS, or COPD scores. Subjects in the Study to Understand Mortality and Morbidity in COPD (SUMMIT) trial were included in the original trial based on the presence of both COPD and cardiovascular risk factors. ${ }^{5,20}$ Utilizing SUMMIT trial subjects and Intermountain patients, this study's aim was to develop and validate a risk score that predicts mortality and other COPD patient outcomes and that can be used to guide treatment decisions in COPD patients.

\section{Methods}

\section{Objectives and Populations}

The primary objective of this study was to derive and validate a risk score, the Summit Score, for all-cause mortality among individuals with moderate COPD. A secondary objective was to risk stratify SUMMIT trial subjects by the Summit Score to identify one or more subsets in which randomly assigned trial medical therapy was more and less effective for preventing mortality. Other secondary objectives (Supplement) were to evaluate the association of the Summit Score with non-fatal outcomes, to derive and validate the Summit Lab Score, and to validate the associations of IMRS and pIMRS with allcause mortality in the SUMMIT trial population. The Intermountain Healthcare Institutional Review Board approved this post hoc evaluation of SUMMIT trial data as a minimal risk study, ${ }^{5}$ and approved evaluation of Intermountain data with a waiver of consent as a minimal risk study.

Populations studied here included subjects from the SUMMIT trial $(\mathrm{N}=16,485)$ who were individuals ages 40-80 years with COPD who had moderate airflow limitation and a history of or elevated risk of cardiovascular disease. ${ }^{5}$ Moderate COPD in SUMMIT was defined as forced expiratory volume in $1 \mathrm{~s}\left(\mathrm{FEV}_{1}\right)$ of $50-70 \%$ of predicted, $\mathrm{FEV}_{1} /$ forced vital capacity $(\mathrm{FVC})$ ratio $\leq 0.70$, history of smoking $\geq 10$ pack-years, and modified Medical Research Council dyspnea scale $\geq 2 .{ }^{5}$ Enrollees were randomly assigned 1:1:1:1 to one of four once-daily treatments: an inhaled placebo, vilanterol (VI) $25 \mu \mathrm{g}$, fluticasone furoate (FF) $100 \mu \mathrm{g}$, or the combination of FF $100 \mu \mathrm{g} / \mathrm{VI} 25 \mu \mathrm{g}{ }^{5}$ Additional details about the SUMMIT trial were previously published. ${ }^{5,20}$ Herein, SUMMIT subjects were randomly divided $50 \% / 50 \%$ into two populations using a binomial random number generator powered by a long-period Mersenne Twister. The first half of SUMMIT subjects constituted the derivation population in which the Summit Score was created and the other half was evaluated for internal validation.

Three Intermountain populations were evaluated as external validations of the Summit Score, with the primary validation being among outpatients with diagnosed COPD and elevated cardiovascular risks. Intermountain outpatients with elevated cardiovascular risks $(\mathrm{N}=9251)$ were ages $40-80$ years with a history of CAD, MI, stroke, peripheral arterial disease, or diabetes, or ages $60-80$ years who were receiving treatments for one or more of the following: hypercholesterolemia, hypertension, or vascular disease, approximating the cardiovascular risk definition from SUMMIT. ${ }^{5}$ Outpatients with COPD but no cardiovascular risks (as defined in SUMMIT, [5] which did not include heart failure) and COPD inpatients were also studied (Supplement). All Intermountain outpatients were managed in an outpatient setting at their first COPD encounter between December 2008 and December 2015. The primary ICD-9 diagnostic codes were 490, 491, 492, $493,494,495$, or 496. ICD-10 was not used since cohort inclusion ended in 2015. For patients with a primary code 
of asthma, COPD was required as a secondary ICD-9 code. Outpatients were followed through March 2018. Mortality was determined from electronic health records, Utah death certificates, and the Social Security death master file. COPD exacerbation (defined as moderate when treated with antibiotics or systemic corticosteroids or as severe when requiring hospitalization) and cardiovascular endpoints (ie, myocardial infarction, unstable angina, stroke, and mortality) were determined from electronic health record data of Intermountain's 22 hospitals and $>180$ clinics that provide health services to about two thirds of the population of Utah and southeast Idaho.

\section{Development of the Summit Risk Scores}

Derivation of the Summit Score was performed in half of SUMMIT subjects $(\mathrm{n}=8181)$ using multivariable Cox regression analysis evaluating all-cause mortality, the primary SUMMIT trial outcome. ${ }^{5,20}$ Variables evaluated in the Cox regression modeling were: age, sex, race, ethnicity, baseline weight, baseline body mass index (BMI), previous treatment for a COPD exacerbation, number of prior hospitalizations for a COPD exacerbation (categorized as 0,1 , or $\geq 2$ ), number of prior treated or hospitalized COPD exacerbations (categorized as 0,1 , or $\geq 2$ ), baseline clinical measures [heart rate (HR), systolic blood pressure (SBP), diastolic blood pressure, $\mathrm{FEV}_{1}, \mathrm{FVC}, \mathrm{FEV}_{1} / \mathrm{FVC}$ ratio], history of smoking, number of pack-years, modified Medical Research Council dyspnea scale score, history of hypertension, history of hypercholesterolemia, diagnosis of diabetes mellitus, previous hospitalization for MI, prior HF diagnosis, previous hospitalization for stroke, history of coronary artery disease (CAD), history of pneumonia, and baseline medications: anti-arrhythmic agents, antihypertensives, anti-thrombotics, beta-blockers, calcium channel blockers, diuretics, inhaled corticosteroids, longacting anticholinergics, long-acting $\beta 2$ agonists, lipid lowering agents, mucolytics, renin-angiotensin-aldosterone system inhibitors, short-acting anticholinergics, and xanthines. Quantitative variables were categorized into quintiles of similar sample size and age was categorized by decade with ages $40-49$ years used as the referent category. Comorbidities and medication variables were categorized as present or absent. Randomized SUMMIT treatments were not considered in the risk score derivation.

Initial analyses used univariable Cox regression to examine each variable above for association with allcause mortality. Multivariable Cox models used both backward and forward stepwise selection of study covariables.
Additional models utilized forced variable entry for those with $\mathrm{p}<0.10$ or confounders (ie, variables causing $>10 \%$ change in another variable's $\beta$-coefficient). The final risk model entered predictors with $\mathrm{p} \leq 0.05$ and variables determined in the model building process to be important contributors to risk stratification. Risk score weightings were assigned based on variables' $\beta$-coefficients from the final model. The risk score was composed as the sum of scalar weightings for each category of each contributing variable based on a modification of the procedure used to compute IMRS. ${ }^{9}$ The scalar weighting for each variable was calculated by subtracting 0.15 from the $\beta$-coefficient, dividing the result by 0.15 , and rounding that value to the nearest integer. Referent categories (e.g., a comorbidity was not present, a medication was not used, or ages $40-49$ years) were assigned a scalar value of zero. Baseline characteristics were evaluated between the SUMMIT derivation and validation populations using the chi-square test for discrete data or the $T$-test for continuous variables. Life table analysis was used to examine mortality rates in each of the derivation and validation populations. C-statistics, sensitivity, specificity, positive predictive value, negative predictive value, and accuracy were also computed for the Summit Score in the derivation and validation populations. The age, dyspnea, airflow obstruction (ADO) index was calculated using standard methodology and c-statistics were calculated. ${ }^{21}$ Analyses were performed in SPSS v.23.0 (IBM SPSS Statistics, Armonk, NY).

\section{Validating the Summit Risk Scores}

To validate the Summit Score, the derived scoring scheme was applied to the SUMMIT validation subjects and the Intermountain validations to predict all-cause mortality. Kaplan-Meier and Cox regression methods were used. Among Intermountain COPD patients, as is common among clinical datasets, most did not have spirometry available [only about $10 \%$ did, as noted previously $\left.{ }^{22}\right]$ and the data were contained in separate clinical machines (in part, this may be due to spirometry being performed in primary care offices or other locations). Further, although tobacco history is collected routinely, data before 2015 did not include electronic capture and thus pack-years were assigned a null value in the Intermountain validations. Quartiles of each score were created separately for each population. A p-value of $\mathrm{p} \leq 0.05$ was required in each independent population for validation. 


\section{Stratification by the Summit Score for the Evaluation of Trial Treatments}

Once validated, the Summit Score was utilized to identify a subset of SUMMIT trial subjects among whom the active treatment of a combination FF $100 \mu \mathrm{g} / \mathrm{VI} 25 \mu \mathrm{g}$ provided a protective mortality benefit compared with placebo, separating those individuals from one or more subsets in whom the benefit was not evident. A minimum of one third of the population with contiguous risk score values was required as a clinically meaningful subset of individuals in whom a benefit may exist. The maximum number of subjects allowable in the subset was not defined because, if it existed, it was necessarily less than the full trial population [the original analysis $(\mathrm{N}=16,485)$ did not find an overall mortality benefit: $\left.\mathrm{HR}=0.88, \mathrm{CI}=0.74,1.04, \mathrm{p}=0.137^{5}\right]$.

To do so, a bar graph was used to assess where a benefit of the FF $100 \mu \mathrm{g} / \mathrm{VI} 25 \mu \mathrm{g}$ combination medication resided and to define the Summit score boundaries of that subset. A search pattern was defined in which no two contiguous Summit Score values could have greater mortality in those receiving FF $100 \mu \mathrm{g} / \mathrm{VI} 25 \mu \mathrm{g}$ than placebo, and at least two thirds of the scores in the subset had to have lower mortality in the FF $100 \mu \mathrm{g} / \mathrm{VI} 25 \mu \mathrm{g}$ arm than placebo. Hazard curves and Cox regression were used to evaluate the trial medications compared with placebo in the subset with benefit and secondarily in the lack of benefit subsets. Secondary endpoints of cardiovascular events, moderate to severe COPD exacerbations, and change in $\mathrm{FEV}_{1}, \mathrm{FVC}$, and the $\mathrm{FEV}_{1}$ /FVC ratio were also evaluated using survival methods or analysis of variance, as appropriate. Other methods are provided in the on-line Supplement.

\section{Results}

Baseline demographics, clinical, risk factor, medication, and other variables for the SUMMIT derivation population and the validation populations are provided in Table 1 . The randomization of SUMMIT subjects into derivation and validation groups resulted in the majority of variables being distributed similarly between the two subpopulations, with just two of the 38 variables listed in Table 1 (ie, RDW and short-acting anticholinergic medications) having statistically significant (but not clinically meaningful) differences.

The derivation of the Summit Score discovered that significant predictors of all-cause mortality were: BMI, number of pack years, number of prior COPD hospitalizations, $\mathrm{FEV}_{1}, \mathrm{HR}$, SBP, prior MI, prior HF diagnosis, prior diabetes diagnosis, age, and prescription of anti- thrombotics, anti-arrhythmics, and xanthines. The c-statistic for the Summit Score in the derivation population was $\mathrm{c}=0.668$, which was comparable to the SUMMIT validation population $(\mathrm{c}=0.662)$ and lower than the Intermountain cardiovascular outpatients $(\mathrm{c}=0.736)$. In comparison, the ADO index had c-statistics of $\mathrm{c}=0.592$ ( $95 \% \mathrm{CI}$ : 0.567 , $0.617)$ in the SUMMIT derivation and $\mathrm{c}=0.618(95 \% \mathrm{CI}$ : $0.593,0.644)$ in the SUMMIT validation populations.

Lengths of longitudinal follow-up and annual mortality rates differed between the populations (Table 1), but the Summit Score was validated as a mortality risk stratification tool in the SUMMIT validation population and Intermountain outpatient validation population (Figure 1, Supplemental Figure S1), with risk differences of 4.4- to 7.6-fold between the lowest and highest risk score quartiles (Table 2, Supplemental Table S1). Examining associations of the Summit Score with mortality among Intermountain populations using quartile thresholds from the SUMMIT validation population resulted in similar findings (Supplemental Table S2 and Supplemental Figure S2). Predictive values and accuracy of the Summit Score are shown in Supplemental Table S3. Associations were also found of the Summit Score with first COPD exacerbation or cardiovascular event (Supplemental Table S4) and with changes in spirometry findings (Supplemental Table S5). Associations are shown for IMRS and pIMRS with mortality in Supplemental Figure S4 and for the Summit Lab Score with mortality in Supplemental Table

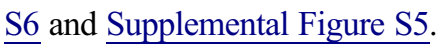

Analyses of the four SUMMIT treatments were performed in risk-based substrata of the combined SUMMIT derivation and validation populations $(\mathrm{N}=16,485)$, with the substrata defined by levels of the Summit Score. Mortality in each Summit Score value (Supplemental Figure S3) identified risk score thresholds that differentiated mortality benefit between subjects taking the combination of FF $100 \mu \mathrm{g} / \mathrm{VI} 25$ $\mu$ g. Among SUMMIT subjects with a Summit Score of 14-19 ( $n=9243)$, Figure 2 reveals that those with the combined FF $100 \mu \mathrm{g} / \mathrm{VI} 25 \mu \mathrm{g}$ treatment had fewer events compared with placebo $(\mathrm{HR}=0.76, \mathrm{CI}=0.61,0.95, \mathrm{p}=0.0158)$. No effect modification was found when an interaction variable of study treatment with SUMMIT derivation/validation was evaluated (for FF $100 \mu \mathrm{g} / \mathrm{VI} 25 \mu \mathrm{g}$ vs placebo: $\mathrm{HR}=0.77 \mathrm{in}$ derivation, $\mathrm{HR}=0.75$ in validation; $\mathrm{p}$-interaction $=0.87$ ). In the Summit Score 14-19 subgroup, FF $100 \mu \mathrm{g} / \mathrm{VI} 25 \mu \mathrm{g}$ also was associated with lower risk of moderate to severe COPD exacerbation $(\mathrm{HR}=0.86, \mathrm{CI}=0.77,0.96, \mathrm{p}=0.005)$ and improved changes in $\mathrm{FEV}_{1}, \mathrm{FVC}$, and $\mathrm{FEV}_{1} / \mathrm{FVC}$ ratio (all $\mathrm{p}<0.001)$ compared with placebo, but not with 
Table I Baseline Characteristics of the SUMMIT Derivation Population and the Four Risk Score Validation Populations

\begin{tabular}{|c|c|c|c|c|c|}
\hline \multirow[t]{3}{*}{ Characteristics } & \multirow[t]{2}{*}{ SUMMIT } & \multirow[t]{2}{*}{ SUMMIT } & \multirow{2}{*}{$\begin{array}{l}\text { Intermountain } \\
\text { Cardiovascular }\end{array}$} & \multirow{2}{*}{$\begin{array}{l}\text { Intermountain } \\
\text { Non-Cardiovasc }\end{array}$} & \multirow[t]{2}{*}{ Intermountain } \\
\hline & & & & & \\
\hline & Derivation & Validation & Outpatients & Outpatients & Inpatients \\
\hline Sample size & $N=8181$ & $N=8304$ & $N=925 \mathrm{I}$ & $N=855 I$ & $N=26,170$ \\
\hline \multicolumn{6}{|l|}{ Demographics } \\
\hline Age (years) & $65.2 \pm 7.9$ & $65.2 \pm 7.9$ & $67.4 \pm 11.0$ & $59.9 \pm 11.5$ & $66.5 \pm 14.6$ \\
\hline Sex (female) & $24.8 \%$ & $26.1 \%$ & $47.4 \%$ & $53.6 \%$ & $46.6 \%$ \\
\hline Race (Non-White) & $18.8 \%$ & $19.1 \%$ & $2.5 \%$ & $2.4 \%$ & $3.5 \%$ \\
\hline Ethnicity (Hispanic) & $6.8 \%$ & $7.5 \%$ & $0.2 \%$ & $0.2 \%$ & $0.5 \%$ \\
\hline Body mass index $\left(\mathrm{kg} / \mathrm{m}^{2}\right)$ & $28.0 \pm 5.9$ & $28.0 \pm 6.0$ & $30.9 \pm 8.6$ & $29.2 \pm 7.9$ & $29.2 \pm 8.8$ \\
\hline \multicolumn{6}{|l|}{ Randomized SUMMIT Trial Treatment } \\
\hline Placebo & $25.0 \%$ & $24.8 \%$ & - & - & - \\
\hline VI 25 & $25.0 \%$ & $25.0 \%$ & - & - & - \\
\hline FF 100 & $24.9 \%$ & $25.3 \%$ & - & - & - \\
\hline FF I00/VI 25 & $25.1 \%$ & $24.9 \%$ & - & - & - \\
\hline \multicolumn{6}{|l|}{ Clinical History (Selected Variables) } \\
\hline Prior COPD exacerbations $(\geq 1)$ & $13.4 \%$ & $13.3 \%$ & $3.6 \%$ & $1.3 \%$ & $5.3 \%$ \\
\hline Prior COPD treatments $(\geq \mathrm{I})$ & $32.4 \%$ & $32.4 \%$ & NA & NA & NA \\
\hline \multicolumn{6}{|l|}{ Number of Prior COPD Hospitalizations } \\
\hline 0 & $86.6 \%$ & $86.6 \%$ & $97.3 \%$ & $99.0 \%$ & $82.1 \%$ \\
\hline 1 & $11.6 \%$ & $11.7 \%$ & $2.7 \%$ & $1.0 \%$ & $13.6 \%$ \\
\hline 2 or more & $1.8 \%$ & $1.6 \%$ & $0 \%$ & $0 \%$ & $4.3 \%$ \\
\hline Heart rate (beats per minute) & $75.8 \pm 9.9$ & $76.0 \pm 9.9$ & $80.7 \pm 15.6$ & $83.6 \pm 15.4$ & $87.8 \pm 19.7$ \\
\hline Systolic blood pressure (mmHg) & $133 \pm 15$ & $133 \pm 15$ & $130 \pm 19$ & $130 \pm 19$ & $133 \pm 26$ \\
\hline $\mathrm{FEV}_{1}(\mathrm{~mL})$ & $1686 \pm 425$ & $1679 \pm 422$ & NA & NA & NA \\
\hline Mean corpuscular volume (fL) & $94.7 \pm 5.9 \dagger$ & $94.8 \pm 6.4 \dagger$ & $91.8 \pm 5.8$ & $92.1 \pm 5.9$ & $92.0 \pm 6.7$ \\
\hline Red cell distribution width (\%) & $15.1 \pm 1.5 \dagger$ & $15.3 \pm 1.6+\ddagger$ & $14.5 \pm 1.8$ & $14.1 \pm 1.7$ & $14.8 \pm 2.2$ \\
\hline \multicolumn{6}{|l|}{ Risk Factors and Comorbidities } \\
\hline Smoking (current) & $46.6 \%$ & $46.5 \%$ & NA & NA & NA \\
\hline Smoking: Pack Years & $41.2 \pm 24.4$ & $40.3 \pm 24.2$ & NA & NA & NA \\
\hline Hypertension & $89.9 \%$ & $90.3 \%$ & $85.8 \%$ & $48.0 \%$ & $73.6 \%$ \\
\hline Hypercholesterolemia & $70.0 \%$ & $69.7 \%$ & $80.4 \%$ & $40.6 \%$ & $55.4 \%$ \\
\hline Diabetes mellitus & $30.2 \%$ & $30.5 \%$ & $42.5 \%$ & $0 \%$ & $25.6 \%$ \\
\hline Myocardial infarction & $15.4 \%$ & $14.8 \%$ & $18.9 \%$ & $0 \%$ & $14.0 \%$ \\
\hline Heart failure & $21.2 \%$ & $20.7 \%$ & $30.7 \%$ & $5.6 \%$ & $23.7 \%$ \\
\hline Stroke & $7.2 \%$ & $6.9 \%$ & $24.8 \%$ & $0 \%$ & $15.5 \%$ \\
\hline Coronary artery disease & $50.8 \%$ & $50.8 \%$ & $63.1 \%$ & $0 \%$ & $42.2 \%$ \\
\hline Pneumonia & $16.5 \%$ & $15.9 \%$ & $42.0 \%$ & $25.0 \%$ & $42.4 \%$ \\
\hline \multicolumn{6}{|l|}{ Baseline Medications } \\
\hline Lipid lowering agent & $65.1 \%$ & $64.6 \%$ & $6.3 \%$ & $1.5 \%$ & $25.9 \%$ \\
\hline Anti-thrombotics & $52.8 \%$ & $52.5 \%$ & $2.5 \%$ & $0.5 \%$ & $25.8 \%$ \\
\hline Beta-blockers & $31.6 \%$ & $31.0 \%$ & $4.9 \%$ & $1.0 \%$ & $26.2 \%$ \\
\hline Diuretics & $32.9 \%$ & $33.2 \%$ & $5.6 \%$ & $1.6 \%$ & $33.2 \%$ \\
\hline Calcium channel blockers & $34.5 \%$ & $34.5 \%$ & $2.8 \%$ & $0.8 \%$ & $14.7 \%$ \\
\hline Anti-arrhythmic agents & $5.4 \%$ & $5.3 \%$ & $2.7 \%$ & $0.9 \%$ & $19.8 \%$ \\
\hline Renin-angiotensin-aldosterone inhib. & $66.9 \%$ & $66.3 \%$ & $5.9 \%$ & $1.8 \%$ & $24.0 \%$ \\
\hline Anti-hypertensives & $4.5 \%$ & $4.7 \%$ & $5.8 \%$ & $1.8 \%$ & $24.4 \%$ \\
\hline Xanthine & $14.6 \%$ & $15.3 \%$ & $0.1 \%$ & $0 \%$ & $0.7 \%$ \\
\hline
\end{tabular}

(Continued) 
Table I (Continued).

\begin{tabular}{|l|l|l|l|l|l|}
\hline Characteristics & SUMMIT & SUMMIT & Intermountain & Intermountain & Intermountain \\
\cline { 3 - 5 } & & & Cardiovascular & Non-Cardiovasc & \\
\cline { 2 - 5 } & Derivation & Validation & Outpatients & Outpatients & Inpatients \\
\hline Short-acting anticholinergic & $10.5 \%$ & $12.1 \% \S$ & $2.6 \%$ & $1.9 \%$ & $23.2 \%$ \\
Mucolytics & $3.0 \%$ & $3.0 \%$ & $0.6 \%$ & $0.2 \%$ & $2.3 \%$ \\
Corticosteroids & $0.6 \%$ & $0.5 \%$ & $4.2 \%$ & $5.5 \%$ & $22.1 \%$ \\
Long-acting beta-2 agonist & $0.4 \%$ & $0.4 \%$ & $3.8 \%$ & $3.2 \%$ & $14.2 \%$ \\
Long-acting anticholinergic & $0.1 \%$ & $0.2 \%$ & $2.5 \%$ & $2.2 \%$ & $9.3 \%$ \\
\hline Mortality Outcomes & & & & & \\
Mortality, total & $6.5 \%$ & $6.1 \%$ & $27.1 \%$ & $12.6 \%$ & $36.8 \%$ \\
Follow-up, mean \pm SD (years) & $1.96 \pm 0.78$ & $1.95 \pm 0.79$ & $6.44 \pm 2.12$ & $6.36 \pm 2.01$ & $4.38 \pm 1.97$ \\
Follow-up, range (years) & $0.88-3.91$ & $0.21-3.91$ & $2.23-9.29$ & $2.25-9.29$ & $0.50-7.50$ \\
Mortality, annual rate & $3.40 \% /$ year & $3.01 \% / y e a r$ & $3.96 \% / y e a r$ & $1.71 \% / y e a r$ & $8.40 \% / y e a r$ \\
\hline
\end{tabular}

Notes: $\nmid$ Laboratory data were only available for $n=1745$ SUMMIT subjects; $\ddagger \mathrm{p}=0.007$ or $\$ \mathrm{p}<0.00 \mathrm{I}$ for the comparison of SUMMIT validation vs derivation populations. Abbreviation: NA, not available.

cardiovascular events $(\mathrm{p}=0.12, \mathrm{HR}=0.81, \mathrm{CI}=0.62,1.06)$. The impact of the medications on mortality in subjects with a Summit Score $\leq 13(n=5610)$ and $\geq 20(n=1632)$ are shown in Supplemental Figures S2B and S2C, and results for secondary outcomes in these subsets are also provided in the Supplement. No difference was found between those assigned to FF/VI or placebo based on Summit Score continuous values $(p=0.36)$ or categorizations $(p=0.22 ; 25 \%$, $25 \%$, and $24 \%$ of subjects received placebo and $24 \%, 25 \%$, $26 \%$ received FF $100 \mu \mathrm{g} / \mathrm{VI} 25 \mu \mathrm{g}$ in Summit Scores $\leq 13$, $14-19$, or $\geq 20$, respectfully).

\section{Discussion}

\section{Summary of Findings}

The Summit Score predicted all-cause mortality among a derivation population from the SUMMIT trial and was validated in the other half of the SUMMIT trial subjects and in Intermountain patients who had moderate COPD and cardiovascular risk factors. The Summit Score also predicted mortality in lower-risk Intermountain outpatients and higher-risk inpatients. Among a substratum of SUMMIT trial subjects with intermediate Summit Scores (ie, scores between 14-19, which constituted $56 \%$ of subjects), SUMMIT treatment with FF $100 \mu \mathrm{g} / \mathrm{VI} 25 \mu \mathrm{g}$ was associated with a lower risk of all-cause mortality; in contrast, no difference in mortality based on trial medical therapy was found in subjects with Summit Scores $\leq 13$ or $\geq 20$. Finally, the Summit Score predicted COPD exacerbations, cardiovascular events (eg, unstable angina, MI, stroke), changes in spirometric measures, incident heart failure, incident cardiac arrhythmias, and coronary revascularization.

\section{COPD, Cardiovascular Disease, and Decision Tools}

COPD is a common complex disease that is challenging to diagnose and requires a thorough and encompassing management approach. ${ }^{1}$ Patients with COPD frequently have other respiratory and cardiovascular comorbidities, some due to the shared risk factor of tobacco use. ${ }^{1,2,23-25}$ COPD severity and prognosis may be stratified by composite risk tools, ${ }^{1}$ such as the BODE Index, ${ }^{26}$ ADO Index, ${ }^{21}$ and DOSE Index, ${ }^{27}$ but these scores use a very limited number of predictors and focus on pulmonary factors. Commonly utilized in COPD populations, these validated scores are the mainstay of risk prediction in pulmonary disease populations. $1,21,26,27$ Analysis of the ADO Index in the derivation and SUMMIT validation populations herein found c-statistics of $0.592-$ 0.618, which were 0.05-0.07 lower than the Summit Score.

Those risk indices were also derived in small populations (fewer than a thousand) with the intended application to all COPD patients. Their use among severely diseased patients or those with complex mixes of morbidities may not fit the originally derivation. $^{21}$ Similarly, while IMRS and pIMRS were predictive of mortality in SUMMIT trial subjects herein, those associations were weaker than in prior evaluations of lower-risk patients. ${ }^{10}$ Given the challenges of applying a risk score to patients with moderate COPD and cardiovascular comorbidities, the Summit Score was developed to attune prediction models to that population. 
A
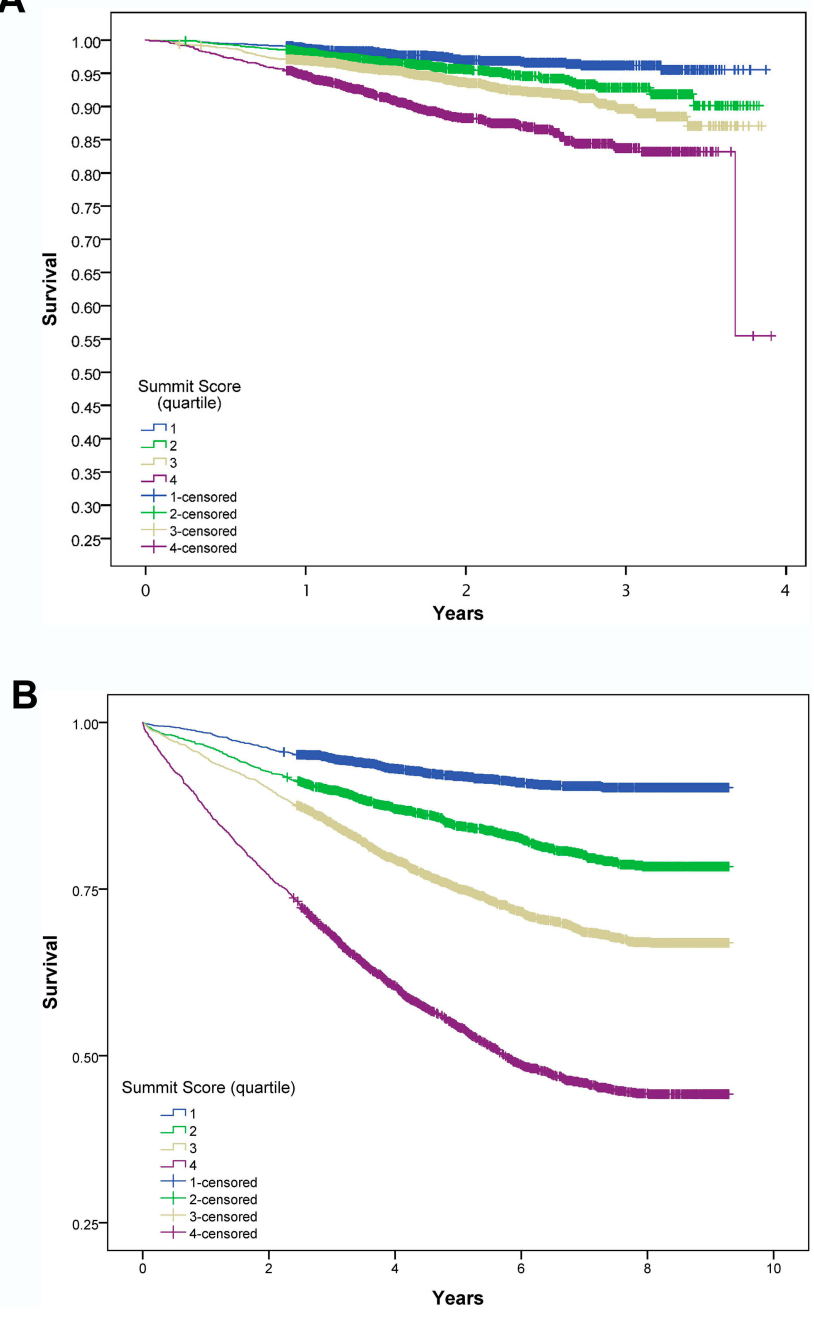

Figure I Kaplan-Meier survival curves displaying the association of the Summit Risk Score with all-cause mortality among: (A) the validation half of the SUMMIT trial population, $\mathrm{N}=8304$ (for quartiles 4,3 , and 2 compared with quartile I: Log rank $p<0.001, p<0.001$, and $p=0.002$, respectively; c-statistic: $c=0.662$ ), (B) an Intermountain Healthcare validation population of outpatients with COPD and cardiovascular risks, $\mathrm{N}=925 \mathrm{I}$ (for quartiles 4,3 , and 2 compared with quartile I: Log rank $p<0.001, p<0.001$, and $p<0.001$, respectively; $c$-statistic: $c=0.736$ ). Time intervals on the $x$-axes were designated in 365 -day intervals for SUMMIT populations and years for Intermountain populations.

To predict mortality, the Summit Score employed a myriad of variables spanning the spectrum of pulmonary disease, cardiovascular disease, and general health. These included clinical exam findings, COPD-specific measurements, cardiovascular parameters, prescription data, and other variables that are not disease-specific. This score utilizes both static and dynamic factors, meaning that some component variables can respond to both positive and negative changes in health (eg, $\mathrm{FEV}_{1}, \mathrm{SBP}$, and RDW). Static factors are strong predictors (eg, experiencing an MI) but will not return to being absent once they occur. While the scores provided moderate risk discrimination in the trial population and were useful in identifying subjects who may receive benefit from FF $100 \mu \mathrm{g} / \mathrm{VI} 25 \mu \mathrm{g}$ treatment, among real-world Intermountain patients the risk differences between Summit Score categories were greater. These findings require further study including whether the Summit Score can identify patients for whom FF $100 \mu \mathrm{g} / \mathrm{VI}$ $25 \mu \mathrm{g}$ is effective in actual practice, and evaluation in implementation science.

Implementation of risk scores in clinical medicine has the goal of achieving best care, whether scores guide a patient care plan or are used to tailor a medication prescription to patient needs. Often today, clinical decision tools such as the Summit Score are used to guide medication prescriptions because the score reveals therapeutic need based on a favorable benefit to risk profile, while indicating which patients do not have a favorable risk-benefit. For example, among atrial fibrillation patients, the $\mathrm{CHADS}_{2}$ and $\mathrm{CHA}_{2} \mathrm{DS}_{2}$-VASc scores are used to identify which patients should receive oral anticoagulation and which excessive bleeding risk. ${ }^{28}$ Among post-stent patients, the DAPT Score is used in determining which patients should receive long-term (ie, $>12$ months) dual antiplatelet therapy after percutaneous coronary intervention. ${ }^{29}$ Instead of guiding a specific medical therapy, IMRS and other scores are used as attention metrics to point clinicians to higher-risk patients and to inform them of which patients require less of their time because they will have the same outcomes from standard care as from intense evaluation and treatment. ${ }^{17}$ This approach is associated with lower 30-day mortality and 30-day readmission in high-risk HF patients, with no worsening of outcomes for lower-risk patients. ${ }^{17}$

The Summit Score has the potential to indicate both therapeutic effect of a medical therapy and to be used as an attention metric for aggressive prevention (see the Supplemental Use Cases). This study suggests that FF $100 \mu \mathrm{g} / \mathrm{VI} 25 \mu \mathrm{g}$ may have varying effectiveness across the spectrum of COPD patients, perhaps due to heterogeneity of disease severity or complexity. A biological rationale exists for the benefit of FF+VI and a reduction in cardiovascular benefits as this combination has been associated with a broad spectrum of anti-inflammatory effects in patients with COPD. ${ }^{30}$ Study limitations are described in the Supplemental Discussion.

\section{Limitations}

This study was challenged by a number of issues in the process of developing a risk score since the predictive 
Table 2 The Association of Quartiles of the Summit Risk Score with All-Cause Mortality in the Internal SUMMIT Validation Population Subset and in the Intermountain Outpatients with COPD and Cardiovascular Risks. As per Table I, Length of FollowUp for Mortality Differed Between Populations

\begin{tabular}{|c|c|c|c|c|}
\hline Summit Score Category & Mortality & Hazard Ratio ( $95 \% \mathrm{Cl})$ & p-value & Sample Size \\
\hline \multicolumn{5}{|c|}{ SUMMIT Trial Internal Validation $(\mathrm{N}=8304)$} \\
\hline Quartile: I (Score: I-12) & $2.6 \%$ & 1.0 (referent) & - & $n=1977$ \\
\hline 2 (Score: 13-14) & $4.5 \%$ & $1.73(1.22,2.45)$ & 0.002 & $n=1813$ \\
\hline 3 (Score: 15-17) & $6.3 \%$ & $2.50(1.83,3.42)$ & $<0.001$ & $n=2664$ \\
\hline 4 (Score: 18-32) & $11.0 \%$ & $4.43(3.27,6.01)$ & $<0.001$ & $n=1850$ \\
\hline \multicolumn{5}{|c|}{ Intermountain COPD Outpatients with Cardiovascular Risks (External Validation) (N=925I) } \\
\hline Quartile: I (Score: 0-9) & $8.5 \%$ & I.0 (referent) & - & $\mathrm{n}=2207$ \\
\hline 2 (Score: I0-II) & $17.9 \%$ & $2.17(1.82,2.59)$ & $<0.001$ & $n=1932$ \\
\hline 3 (Score: $12-14)$ & $28.4 \%$ & $3.59(3.06,4.21)$ & $<0.001$ & $\mathrm{n}=2795$ \\
\hline 4 (Score: 15-26) & $50.9 \%$ & $7.62(6.53,8.89)$ & $<0.001$ & $n=2317$ \\
\hline
\end{tabular}

performance is critically determined by the available data and the nature of the populations studied. One was that the primary study population consisted of individuals who were selected for inclusion in a large prospective randomized clinical trial based on stringent criteria and are unlikely to be broadly representative of clinical practice. ${ }^{5,20}$ Actual medical practice includes a broad range of patients rather than those with a tightly defined COPD diagnosis as in a trial, which

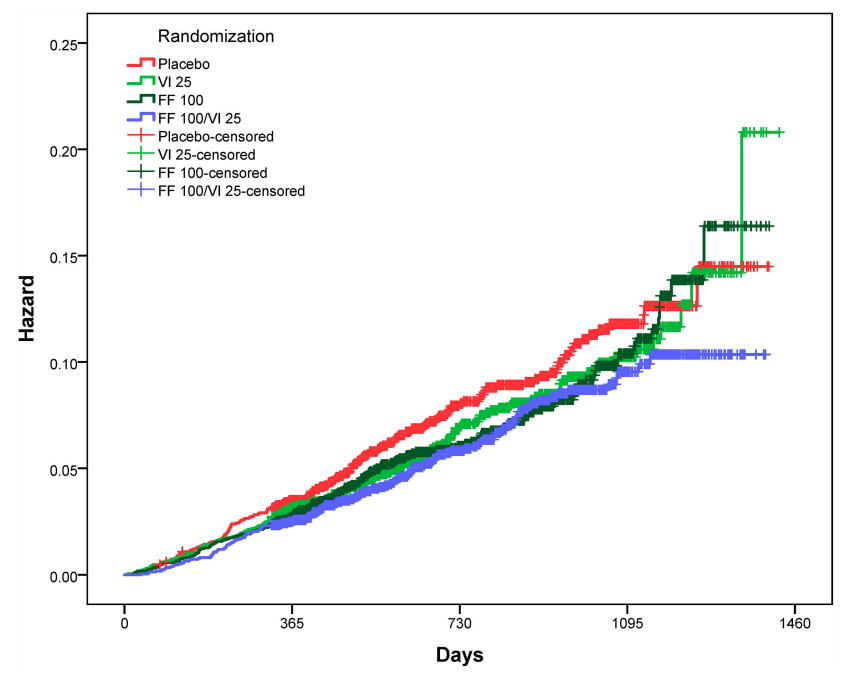

Figure 2 Hazard curves for the effects of the four SUMMIT trial randomized treatments on all-cause mortality among all SUMMIT trial subjects (ie, both the Summit Score derivation and validation groups). Trial randomizations included: once daily inhaled placebo, vilanterol (VI) $25 \mu \mathrm{g}$, fluticasone furoate (FF) $100 \mu \mathrm{g}$, or the combination of FF I00 $\mu \mathrm{g}$ and VI $25 \mu \mathrm{g}$. Here the combination of FF I00 $\mu \mathrm{g} / \mathrm{VI} 25 \mu \mathrm{g}$ $(n=2347)$ had a statistically significantly lower mortality compared with placebo $(n=2305)(p=0.0158, H R=0.76, C l=0.61,0.95)$ among subjects with a Summit Score $\geq 14$ and $\leq 19$ ( $n=9243$, which is $56.1 \%$ of the SUMMIT trial subjects). The hazard curves for subject with Summit Score $\leq 13$ and $\geq 20$ are provided in Supplemental $\underline{\text { Figures } \mathrm{S} 2 \mathrm{~B}}$ and $\underline{\mathrm{S}} \mathrm{C}$. may in part account for the greater ability for the Summit Score to stratify risk in the three Intermountain populations given that some parameters were not necessarily pulmonary-related. Further, the Intermountain clinical population was limited because a few Summit Score parameters were not available (i.e., $\mathrm{FEV}_{1}$-which was unavailable for $\approx 90 \%$ of patients and for the few who did have spirometry data it was housed in a proprietary vendor database not accessible to study personnel, and smoking status which was unavailable outside of free text reports).

Secondly, this study derived the risk scores among subjects in whom three quarters were assigned an active medication in the SUMMIT trial that may have some effect on mortality (the other quarter received placebo). The derivation of the score, though, did not account for the treatment variable so that subsequent analysis could examine using the score for therapeutic risk stratification. Analysis showed that the percentage of subjects receiving each medication assignment did not differ across levels of the risk score, indicating that the score did not include the treatment effects. If any bias existed due to the treatment effects, thus, it was toward the null hypothesis. Finally, despite that the c-statistics for mortality in the SUMMIT population were of only moderate strength, the risk was strongly stratified by the Summit Score. Further evaluation of the score is needed in additional populations and in studies using the risk score to identify people who will benefit from combined FF $100 \mu \mathrm{g} /$ VI $25 \mu \mathrm{g}$ treatment. Because the SUMMIT Trial did not use ICD codes and the Intermountain cohort inclusions ended in 2015, ICD-10 coding was not evaluated herein and could provide improved resolution. 


\section{Conclusions}

The Summit Score was developed and validated in geographically and constituently distinct populations as a predictor of all-cause mortality. It also predicted COPD and cardiovascular endpoints. When modified to include common laboratory panels (ie, CBC and BMP), the resulting Summit Lab Score also predicted those outcomes (see Supplement). Uniquely, the Summit Score identified a subset of individuals with similar risk levels who may receive therapeutic benefit from a combination of FF $100 \mu \mathrm{g} / \mathrm{VI} 25 \mu \mathrm{g}$, which requires additional evaluation and validation. Further study of these therapeutic risk scores in research and clinical implementation environments is indicated.

\section{Abbreviation}

ADO, age, dyspnea, airflow obstruction; BMI, body mass index; $\mathrm{BMP}$, basic metabolic profile; $\mathrm{CAD}$, coronary artery disease; CBC, complete blood count; COPD, chronic obstructive pulmonary disease; $\mathrm{FEV}_{1}$, forced expiratory volume in $1 \mathrm{~s}$; FF, fluticasone furoate; FVC, forced vital capacity; HF, heart failure; HR, heart rate; hsCRP, highsensitivity C-reactive protein; IMRS, Intermountain Mortality Risk Score; MCV, mean corpuscular volume; MI, myocardial infarction; pIMRS, pulmonary Intermountain Mortality Risk Score; RDW, red cell distribution width; SBP, systolic blood pressure; SUMMIT, study to understand mortality and morbidity in COPD; VI, vilanterol.

\section{Data Sharing}

Information on GlaxoSmithKline plc's data sharing commitments and requesting access to anonymized individual participant data and associated documents can be found at www. clinicalstudydatarequest.com. Intermountain Healthcare patient data are protected by law but may be accessed through collaborative contract by contacting Dr. Horne (benjamin.horne@imail.org).

\section{Acknowledgments}

The authors thank the SUMMIT Steering Committee members for the approval to conduct this study in the SUMMIT Trial data: Jorgen Vestbo (co-chair, UK), Robert D Brook (USA), Peter M A Calverley (UK), Bartolome R Celli (USA), Fernando Martinez (USA), David E Newby (UK), Courtney Crim, (co-chair, GlaxoSmithKline, USA), Julie A Anderson (GlaxoSmithKline, UK), and Julie Yates (GlaxoSmithKline, USA).

\section{Author Contributions}

BDH had full access to all study data, takes responsibility for the integrity of the data and the accuracy of the data analysis, and had authority over manuscript preparation and the decision to submit the manuscript for publication. Conception and design: $\mathrm{BDH}, \mathrm{MJH}, \mathrm{CC}, \mathrm{DPB}$; acquisition, analysis, or interpretation of data: $\mathrm{BDH}, \mathrm{MJH}, \mathrm{CC}, \mathrm{SR}, \mathrm{TLB}, \mathrm{DPB}$; drafting of the manuscript: $\mathrm{BDH}$; critical revision for important intellectual content: BDH, MJH, CC, SR, TLB, DPB; final approval of the submitted manuscript: $\mathrm{BDH}, \mathrm{MJH}, \mathrm{CC}$, SR, TLB, DPB; agreement to be accountable for all aspects of the work: BDH, MJH, CC, SR, TLB, DPB. All authors contributed to data analysis, drafting or revising the article, gave final approval of the version to be published, and agree to be accountable for all aspects of the work.

\section{Funding}

This study was funded by an in-kind grant from GlaxoSmithKline and by a grant from the Intermountain Healthcare Foundry innovation program. The funding sources had no role in the design of the study, the data analysis, the interpretation of the findings, or the writing or publication of the study manuscript.

\section{Disclosure}

$\mathrm{BDH}$ is an inventor of clinical decision tools that are licensed to CareCentra and Alluceo and is the PI of grants related to clinical decision tools that were funded by Intermountain Healthcare's Foundry innovation program, the Intermountain Research and Medical Foundation, CareCentra, GlaxoSmithKline, and AstraZeneca. DPB and $\mathrm{MH}$ received research funding through AstraZeneca. DPB received grants outside the submitted work from ProLung and ZebraMedical. CC is employed by and holds restricted shares in GlaxoSmithKline. No other potential conflicts of interest exist.

\section{References}

1. Vogelmeier CF, Criner GJ, Martinez FJ, et al. Global strategy for the diagnosis, management, and prevention of chronic obstructive lung disease 2017 report: GOLD executive summary. Eur Respir J. 2017;49 (3):1700214. doi:10.1183/13993003.00214-2017

2. Fabbri LM, Luppi F, Beghé B, Rabe KF. Complex chronic comorbidities of COPD. Eur Respir J. 2008;31:204-212. doi:10.1183/ 09031936.00114307

3. McGarvey LP, John M, Anderson JA, Zvarich M, Wise RA. Ascertainment of cause-specific mortality in COPD: operations of the TORCH clinical endpoint committee. Thorax. 2007;62:411-415. doi:10.1136/thx.2006.072348 
4. Calverley PMA, Anderson JA, Celli B, et al. Salmeterol and fluticasone propionate and survival in chronic obstructive pulmonary disease. N Engl J Med. 2007;356:775-789. doi:10.1056/NEJMoa063070

5. Vestbo J, Anderson JA, Brook RD, et al.; on behalf of the SUMMIT Investigators. Fluticasone furoate and vilanterol and survival in chronic obstructive pulmonary disease with heightened cardiovascular risk (SUMMIT): a double-blind randomized controlled trial. Lancet. 2016;387:1817-1826. doi:10.1016/S0140-6736(16)30069-1

6. Sin DD, Wu L, Man SF. The relationship between reduced lung function and cardiovascular mortality: a population-based study and a systematic review of the literature. Chest. 2005;127(6):1952-1959. doi:10.1378/chest.127.6.1952

7. Lee HM, Le H, Lee BT, Lopez VA, Wong ND. Forced vital capacity paired with Framingham risk score for prediction of all-cause mortality. Eur Respir J. 2010;36(5):1002-1006. doi:10.1183/0903 1936.00042410

8. Smith LJE, Moore E, Ali I, Smeeth L, Stone P, Quint JK. Prognostic variables and scores identifying the end of life in COPD: a systematic review. Int J Chron Obstruct Pulmon Dis. 2017;12:2239-2256. doi:10.2147/COPD.S137868

9. Horne BD, May HT, Muhlestein JB, et al. Exceptional mortality prediction by risk scores from common laboratory tests. Am J Med. 2009;122:550-558. doi:10.1016/j.amjmed.2008.10.043

10. Horne BD, Hegewald M, Muhlestein JB, et al. Pulmonary-specific intermountain risk score predicts all-cause mortality via spirometry, the red cell distribution width, and other laboratory parameters. Respir Care. 2015;60:1314-1323. doi:10.4187/respcare.03370

11. Horne BD, Lappé DL, Muhlestein JB, et al. Repeated measurement of the intermountain risk score enhances prognostication for mortality. PLoS One. 2013;8:e69160. doi:10.1371/journal.pone.0069160

12. Majercik S, Knight S, Horne BD. The intermountain risk score predicts mortality in trauma patients. J Crit Care. 2014;29:882.e1-4. doi:10.1016/j.jcrc.2014.03.016

13. Rassa AC, Horne BD, McCubrey RO, et al. Novel stratification of mortality risk by kidney disease stage. Am J Nephrol. 2016;42:443-450. doi:10.1159/000443776

14. Horne BD, Anderson JL, Muhlestein JB, Ridker PM, Paynter NP. The complete blood count risk score and its components including the RDW are associated with mortality in the JUPITER Trial. Eur J Prev Cardiol. 2015;22:519-526. doi:10.1177/2047487313519347

15. APP R, Sangoi MB, de Paiva LG, Parcianello J, da Silva JE, Moresco RN. Complete blood cell count risk score as a predictor of in-hospital mortality and morbidity among patients undergoing cardiac surgery with cardiopulmonary bypass. Int $J$ Cardiol. 2015;187:60-62. doi:10.1016/j.ijcard.2015.03.227

16. Horne BD, May HT, Kfoury AG, et al. The intermountain risk score (including the red cell distribution width) predicts heart failure and other morbidity endpoints. Eur J Heart Fail. 2010;12:1203-1213. doi:10.1093/eurjhf/hfq115

17. Horne BD, Roberts CA, Rasmusson KD, et al. Risk score-guided multidisciplinary team-based care for heart failure inpatients is associated with lower 30-day readmission and lower 30-day mortality. Am Heart J. 2020;219:78-88. doi:10.1016/j.ahj.2019.09.004
18. May HT, Anderson JL, Muhlestein JB, Lappé DL, Ronnow BS, Horne BD. Improvement in the predictive ability of the intermountain mortality risk score by adding routinely collected laboratory tests such as albumin, bilirubin, and white cell differential count. Clin Chem Lab Med. 2016;54:1619-1628. doi:10.1515/cclm-2015-1258

19. Horne BD, Muhlestein JB, Bhandary D, et al. Clinically feasible stratification of 1- to 3-year post-myocardial infarction risk. Open Heart. 2018;5:e000723. doi:10.1136/openhrt-2017-000723

20. Vestbo J, Anderson J, Brook RD, et al. The Study to Understand Mortality and Morbidity in COPD (SUMMIT) study protocol. Eur Respir J. 2013;41:1017-1022. doi:10.1183/09031936.00087312

21. Puhan MA, Garcia-Aymerich J, Frey M, et al. Expansion of the prognostic assessment of patients with chronic obstructive pulmonary disease: the updated BODE index and the ADO index. Lancet. 2009;374(9691):704-711. doi:10.1016/S0140-6736(09)61301-5

22. Blagev DP, Collingridge DS, Rea S, et al. The Laboratory-based Intermountain Validated Exacerbation (LIVE) score identifies chronic obstructive pulmonary disease patients at high mortality risk. Front Med. 2018;5:173. doi:10.3389/fmed.2018.00173

23. Song S, Yang PS, Kim TH, et al. Relation of chronic obstructive pulmonary disease to cardiovascular disease in the general population. Am J Cardiol. 2017;120:1399-1404. doi:10.1016/j.amjcard.2017.07.032

24. Bhatt SP, Dransfield MT. Chronic obstructive pulmonary disease and cardiovascular disease. Transl Res. 2013;162:237-251. doi:10.1016/j. $\operatorname{trs} 1.2013 .05 .001$

25. Høiseth AD, Neukamm A, Karlsson BD, Omland T, Brekke PH, Søyseth V. Elevated high-sensitivity cardiac troponin $\mathrm{T}$ is associated with increased mortality after acute exacerbation of chronic obstructive pulmonary disease. Thorax. 2011;66:775-781. doi:10.1136/ thx.2010.153122

26. Celli BR, Cote CG, Marin JM, et al. The body-mass index, airflow obstruction, dyspnea, and exercise capacity index in chronic obstructive pulmonary disease. $N$ Engl J Med. 2004;350(10):1005-1012. doi:10.1056/NEJMoa021322

27. Jones RC, Donaldson GC, Chavannes NH, et al. Derivation and validation of a composite index of severity in chronic obstructive pulmonary disease: the DOSE index. Am J Respir Crit Care Med. 2009;180:1189-1195. doi:10.1164/rccm.200902-02710C

28. January CT, Wann LS, Alpert JS, et al. 2014 AHA/ACC/HRS guideline for the management of patients with atrial fibrillation: executive summary: a report of the American College of Cardiology/American Heart Association Task Force on practice guidelines and the Heart Rhythm Society. Circulation. 2014;130:2071-2104. doi:10.1161/ CIR.0000000000000040

29. Yeh RW, Secemsky EA, Kereiakes DJ, et al.; DAPT Study Investigators. Development and validation of a prediction rule for benefit and harm of dual antiplatelet therapy beyond 1 year after percutaneous coronary intervention. JAMA. 2016;315:1735-1749. doi:10.1001/jama.2016.3775

30. Barnes NC, Qiu YS, Pavord ID, et al.; SCO30005 Study Group. Antiinflammatory effects of salmeterol/fluticasone propionate in chronic obstructive lung disease. Am J Respir Crit Care Med. 2006;173:736-743. doi:10.1164/rccm.200508-13210C

International Journal of Chronic Obstructive Pulmonary Disease

\section{Publish your work in this journal}

The International Journal of COPD is an international, peer-reviewed journal of therapeutics and pharmacology focusing on concise rapid reporting of clinical studies and reviews in COPD. Special focus is given to the pathophysiological processes underlying the disease, intervention programs, patient focused education, and self management protocols. This journal is indexed on PubMed Central, MedLine and CAS. The manuscript management system is completely online and includes a very quick and fair peer-review system, which is all easy to use. Visit http://www.dovepress.com/testimonials.php to read real quotes from published authors. 